\title{
IMPERMANENT ART- THE ESSENCE OF BEAUTY IN IMPERFECTION
}

Helen Plumb

plumbpudding@hotmail.co.uk

The notion of beauty as imperfection has become more significant over the last century. Directly related to advances in technology, it is the capabilities that technologies provide in making it possible to get closer to the ideal, perfect form that have challenged what constitutes beauty. Focusing on Interactive art, the idea that beauty can be found in an impermanent space shall be explored. What is it that moves us about a rare moment that will not last?

\section{BEAUTY, PERFECTION AND THE IDEAL}

When we say that something is perfect we mean that it is 'complete'. Beauty is measured by its completeness. It has met the limits of its criteria and this also suggests that there are in fact universal 'rules' that art must follow in order for the judgement of beauty to be made. This judgement of beauty is an objective one. The birth of geometry enabled the Greek's to measure aesthetic value based on geometrical study which led to the discovery of 'Golden section'. This was a mathematical solution that determined the perfect proportion.

Throughout history the origins of beauty have been debated. For Plato, the universal idea of beauty had an objective existence. In Plato's Republic, art can only come close to beauty while attempting to copy form perfectly. Beauty is a question of harmony and proportion. Perfect proportions cannot be realised in the ideal. We can conceptualise a perfect circle but it is impossible to draw one. As a result, beauty of the mind is more superior and leads to 'the beauty itself': the concept of universal beauty. For Plato, Beauty holds an a priori existence.

Kantian forms of intuition should also be acknowledged. In making a distinction between the object and the representation of the object, attention is drawn to the notion that beauty resides in the relationship between the viewer and the object. Therefore, the judgement of beauty is based on how this representation makes us feel. Not whether the representation of the object provides empirical knowledge (much like platonic analysis) but whether it provides an intuitive experience of it.

In order to make a judgement of pure beauty, the viewer has to take a disinterested view, one that is non-conceptual.

The notion of an aesthetic judgement made without moral or sensory concepts has been heavily contested, as it is impossible to conceive of something outside of conceptualisation or imagine that the pleasure we derive from something can be present independently of trying to comprehend it. Allison [1] 
Refuting the Platonic and classical position, Kant contends that whilst judgements of pure beauty are not grounded in any definite concepts, judgements of perfection have a concept of the object's ideal condition in mind. Perfection is quite different to pure beauty. Kant instead defines perfection as adherent or dependent beauty. It is a purposerelated beauty, adhering to sensory charm. It is a beauty of purposive nature [6], a more conceivable definition.

We can chose to take from this that regardless of whether beauty holds an a priori existence or one that is a human construct, perfection can be described as being related to form.

In contemporary art, we now have the technology to produce art that has the potential to interpret form perfectly. Photography has enabled us to produce exact copies of natural form and photo manipulation software allows us to illustrate 'perfect' beauty in a much more heightened manner. This can be achieved through altering the composition and manipulating human form to create the 'ideal'.

\section{IMPERFECT BEAUTY}

Although new technology can create such perfection and a heightened sense of beauty, we seem to be regressing in the progress of absolute perfection and producing art that is ultimately and quite intentionally imperfect. This is not a regression in technology as technology continually advances; it is instead advancing in order to undo the portrayal of perfection. The demand for this type of aesthetic suggests that in fact beauty can be found in imperfection. For example, it is commonplace nowadays to see computer made art that has grunge filters applied in order to give the appearance of an aged object.

One explanation for an imperfect aesthetic could be due to the appeal of that which is authentic, art that is truer to life and not an ideal form. A large proportion of contemporary art is created for the purpose of reproduction. These arts come in such forms as: photography, film, print and computer art. As there are no authentic versions, they are described as arts that are designed to make multiple copies.

Walter Benjamin argues that an authentic piece of artwork holds a certain aura [7]. He defines aura as something that has a presence in time and space. Its unique existence determines its history. This includes any changes the artwork may have gone through, such as decay or changes in ownership. Whilst the significance of an object changes with tradition, its uniqueness is preserved. The presence/uniqueness of the original denotes its authenticity and thus becomes an object of aura.

Benjamin also contends that the development in technology that has led to mass reproduction has resulted in a decay of aura. A technically (not manually) reproduced piece of work detaches the reproduced object from the domain of tradition. When the historical testimony is threatened, the authority of the object is affected, resulting in the loss of aura. A separation has occurred between the original and the mechanically reproduced version. The notion of aura, therefore, has a possible effect on the 
judgement of beauty. It could be said that a loss of aura has resulted in the referencing of authenticity in aesthetics, in the form of imperfection.

The idea of aura implies an authenticity. However, there is no authenticity without its destruction in mechanical reproduction. As recognised by Harmen, the idea of authenticity only emerges when it is threatened [9].

Only through mechanical reproduction can authenticity be referenced and if aura only exists with the invention of mass reproduction, this may explain a need for imperfection in potentially perfect objects. For example, a print that has been misprinted (what should in theory be a perfect stroke is mottled or has bled) gives a viewer a sense of its history and its producer; even though many other copies exist that have the same misprint. Advances in technology have a direct link to the appeal of imperfection.

This could be described as an evolutionary change in aesthetic judgement due to technological development. The changes that are evident in aesthetics are subversive to the destruction in aura that is brought about by mass reproduction. There is evidence in mass-reproduced art that challenges Benjamin and Plato by suggesting that perception of beauty is not relevant to space and time and does not require a need for perfection. So, art can be beautiful because it is incomplete. As we shall now discuss, this does not just apply to form but in the experience of viewing.

Improvisational art both satisfies the need for authenticity and challenges the significance of aura in art in terms of its relevance to space and time. To illustrate this point we shall look at the improvisational process of jazz, which seems to sit outside of what Benjamin constitutes as art.

In his discussion of mechanical reproduction, Benjamin identifies two categories of art. One category is defined as: work of art designed for reproducibility and the other as: pre-reproduction artwork. It is noted by Coulthard that jazz cannot be described as 'work of art designed for reproducibility' because it existed decades before the invention of recording [8]. However it also cannot be described as pre-production artwork because prior to the first recordings jazz was rarely written down and therefore does not have a historical existence. Its existence is in the transitory space of performance and this suggests that jazz lacks the physical place of origin that is necessary for the possession of aura.

Both written scores of jazz and recorded jazz containing head arrangements and chord progression provide a framework for spontaneity and improvisation. Jazz is a good example of artwork that is not bound to space and time yet has an aesthetic process in which beauty can be found. It could be described as impermanent art of which its beauty can be found in its imperfection. We could say that the appeal of imperfection is that it represents the changing nature that is true to life.

The Buddhist and Tao philosophy of Wabi Sabi also seeks to find beauty in imperfection. It is an appreciation for things found in a constant state of flux. It seeks beauty in the truths of the natural world, these truths being that everything in the natural world is in perpetual movement- impermanent and ever changing. This Japanese 
aesthetic is most commonly found in things that are in decay, and death. As outlined by Juniper:

Rooted firmly in Zen thought, Wabi Sabi art uses the evanescence of life to convey the sense of melancholic beauty that such an understanding brings.[5]

Wabi Sabi art could be described as a more accurate interpretation of the world contrary to technological developments that practice the art of perfection. Nothing in reality is perfect or completely still, this idea only exists conceptually.

On the one hand we could say that Wabi Sabi completely supports Benjamin's notion of a loss of aura in mechanical reproduction. The nature of arts that are created for the purpose of reproduction means that art, in theory, never goes through the process of change. It needn't age nor decay and as an object of reproduction has lost its presence in time and space.

However, when considering more contemporary art forms which also encompass mass reproduction, such as digital art, we can see how imperfection and impermanence in art are represented. The Wabi Sabi aesthetics could also be found in arts that neither strive for perfection nor have a fixed position in time and space. These are improvisation art and as we shall discuss, interactive art.

\section{BEAUTY IN INTERACTION AND ALTERNATIVE SPACES}

It could be argued that art created for mass reproduction has progressed further in favour of a more subjective experience, subverting the idea of a mass culture and embracing the idea of impermanence. The subversion being referred to here is the art of imperfection, in the form of impermanence, in favour of a less objective view. The art we are focusing on here is Interactive Art, which provides a subjective experience in which the beauty is found in the "self- reflexive relationship between oneself and the work of art". Ascott [1]

Interactive Arts that are technically reproducible can also provide this kind of subjective experience based on impermanence. Cybernetics is a scientific discipline that studies the process of communication, particularly the control of communication. The premise being that to make something happen, actions must be taken and to achieve an outcome requires some form of feedback.

Cybernetics operates using constraints, much like the theory of evolution. In evolution, natural selection happens by eliminating what does not fit as opposed to creating selection.

Although it started out as a science, Cybernetics entered the art world in the 1960 with such exhibitions as 'this is tomorrow' and Cybernetics and Serendipity. One of the first people to create work of this nature and give cybernetics an artistic context was Pask. At the Cybernetics and Serendipity exhibition in 1968, Pask displayed 'The Colloquy of Mobiles', a computer based system consisting of 5 mobiles. These were machines that 
could interact with people and each other. He referred to the installation as an aesthetically potent environments designed to stimulate pleasurable interactions [2].

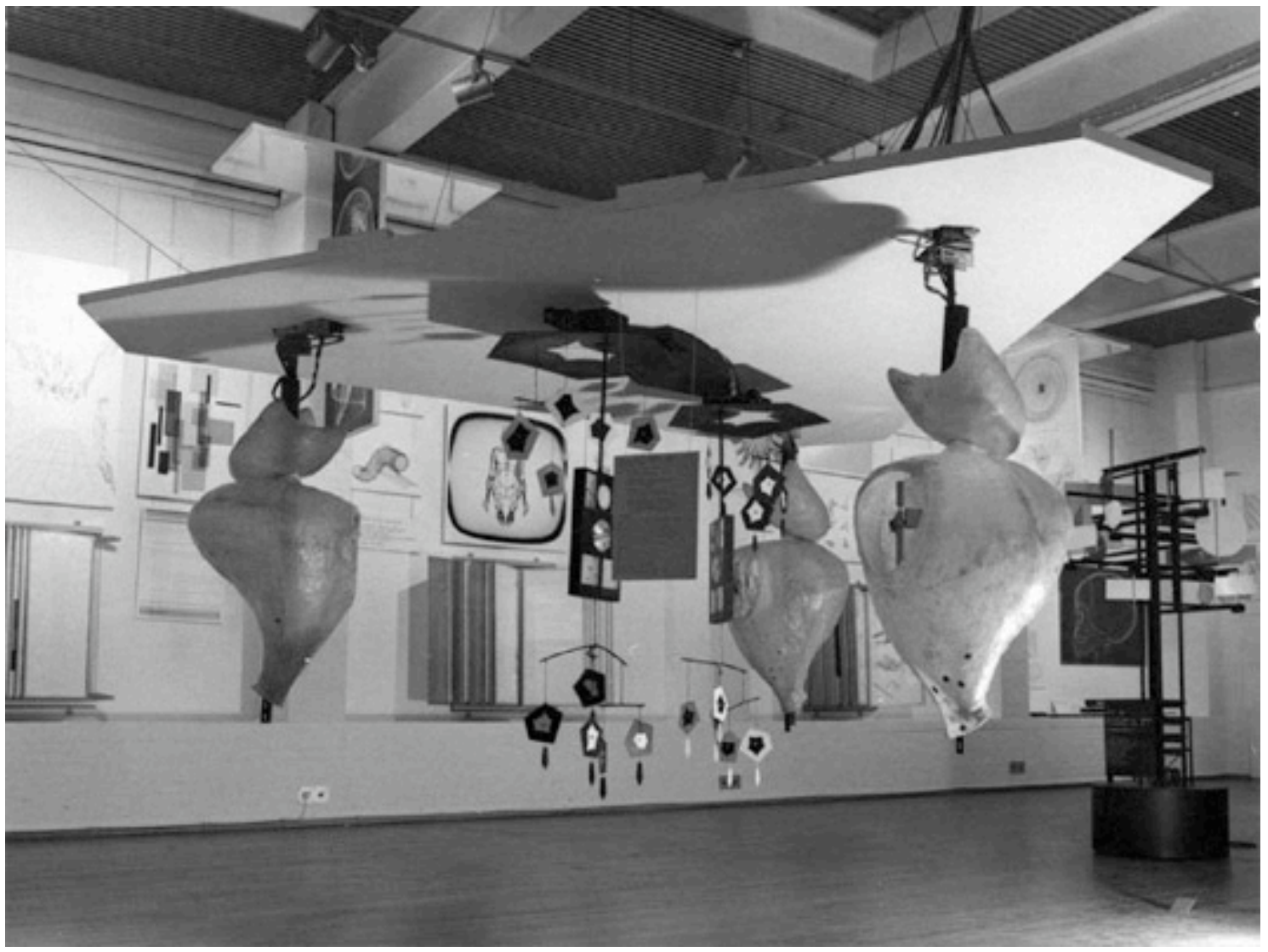

Fig. 1. The Colloquy of Mobiles

Pask's ideas of self-organised systems influenced later developments in digital art in the early 1970s by Myron Krueger. His concept of "responsive environments" was used to create artworks that responded to the movement and gesture of the viewer [10]. He used floors with sensors and video cameras.

"Roots", (see fig. 2) created by Roman Kirschner demonstrates how the theory behind Cybernetics is used today. Inspired by Pask's work, Roots is a fluid tank that grows iron crystals. Electrical wires are pulsed through branch like wires, encouraging the crystals to grow. The growth changes the flow of the current, which in turn manipulates the growth. The results of this exchange produce an organic display and an evanescent experience. 


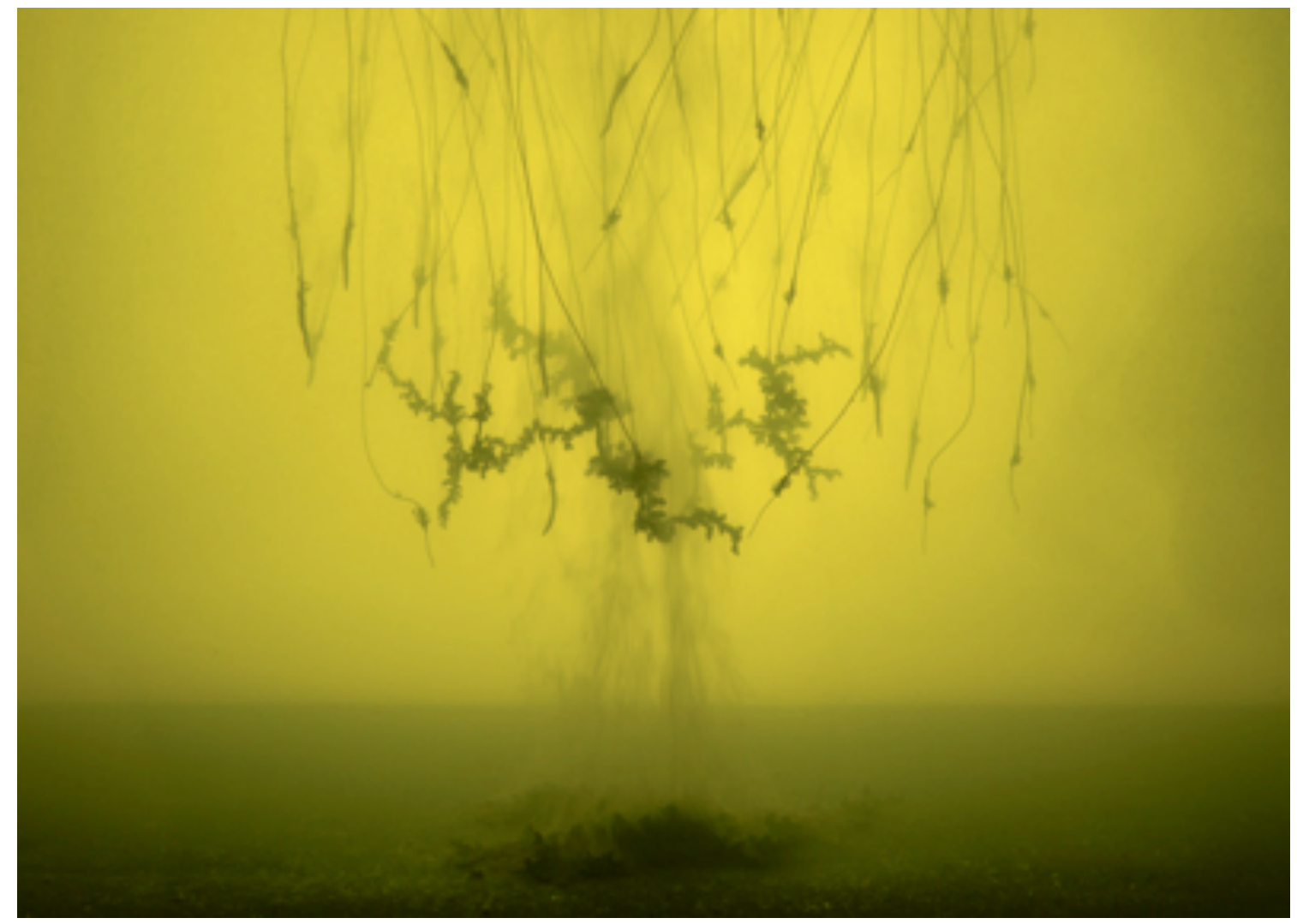

Fig. 2. Roots

In the context of imperfect impermanent art, cybernetics shares an integral partinteraction and feedback. For impermanent art to 'work' the process of interaction has to take place, whether that is between the art and the viewer, the art and its environment or the art and itself. Interactive Arts are all reproducible in the sense that they are built on a transferable model, which is intrinsic but separable from the artistic experience.

What is it that gives this type of impermanent art the aesthetic of beauty?

\section{BEAUTY IN WONDER}

It is possible that the emotional response of wonder is present in the beauty of impermanence. Descartes spoke of Wonder as the first of 6 primitive passions, the others being, love, hate, joy, sadness and desire. The emotion of wonder is a passion of the soul, a mental state that arises as a result of brain activity. It produces a feeling of surprise that is present when observing something that it rare and extraordinary [3].

Wonder is the first passion for Descartes because it is a pleasure that comes before all others. To wonder at something that is rare or extraordinary moves us to learn more about it. Perhaps impermanent art is connected to the aesthetics of rare experiences and wonder is at play in producing moments of beauty. 
In his analysis of wonder and the sublime, Fisher argues that wonder has been neglected as a category of the aesthetics of rare experiences [4].

The appeal of wonder along with 'newness' is not the inability to understand the thing in question but the idea that it is something we don't quite get. It is a stimulus to cognition. It is the process of thoughts or 'steps of thoughts' that are the experience of wonder. The delight comes with the anticipation of the results and an intellectual effort to make sense of something new. Wonder leads to intelligibility or partial intelligibility. In this sense we can see how cybernetics continues to be developed, it is not necessarily the outcome that is important but the process involved in getting there via feedback.

Francis Bacon referred to wonder as 'broken' knowledge' and suggested that it acted as the impulse to repair or add to the imperfect or incomplete body of knowledge. Socrates first acknowledged this impulse in the platonic dialogue Theaetetus, as the beginning of philosophy. Later, Descartes restated this as "human existence begins in wonder." [4.1]

The experience of wonder is a symptom of human intellect as explained in Fisher's example of the beauty of rainbows. The experience of seeing a rainbow relies on three elements, light, the observer and water. The scientific principle is that light passes through water droplets where it refracts then reflects off the back of the droplet and refracts again to reach the observer to display the different colours that make up light. These events are visible only when the observer is at the correct angle, 42 degrees between the sun and the water droplet. As it is dependent on these three features, the rainbow can be described as a rare experience and the very specific requirements such as the angle of the observer, makes the experience unique and subjective to each observer. This is when we experience a moment of wonder. A rainbow is always rare, impermanent and therefore evokes feelings of surprise and the unexpected.

One vital question about the aesthetics of wonder in art is that if wonder intrinsically requires newness and unexpectedness, do these types of artwork become stale and uninteresting once an explanation has been provided for them? For Fisher this is true of the aesthetics of shock and the sublime. The neglect he talks about of wonder over the sublime has led in to dissatisfaction in post-modern art. The shock factor becomes quickly tiresome because it doesn't appeal to our drive for intelligibility. Wonder does not concern the value of shock, it is only odd or obscure things that are considered 'new'. Fisher suggests that art that isolates recognition is also 'new' and this provokes the thought process of wonder. As memory, a basis for recognition, allows us to recognise details of our own traditions and supply us with instant answers. It does not lead us to intelligibility.

Applying this theory to the work of Olafur Eliasson, we can see how the process of explanation creates wonder. Eliasson's works deal with the politics of enchantment; they are evanescent and impermanent experiences. In his installation entitled beauty (see fig. 3) installed at The Museum of Contemporary Art, Los Angeles 2003 Eliasson constructed a wall of mist under a spotlight in a dark room. When the viewer moves around the room they can find a rainbow in the mist.

What is interesting about this piece is that the aesthetic has been partially demystified by the fact that he doesn't hide the workings of the installation. We see all the apparatus 
used in the piece, the spotlight, and the machine that produces the mist. The aspect of wonder is not lost in this; the exposure aids and prolongs the experience of wonder. The process of explanation consists of both knowledge and error. Throughout history we have been given partially successful explanations about how a rainbow works, it remains mystifying because light itself has no explanation. We have both a wave and a particle theory of light. We use a mixture of false components of knowledge and 'local intelligibility' knowledge we consider certain based on our own cultural traditions, in a moment of wonder. It is human nature that we proceed with trial and error, this is one of the elements of the poetics of thought. We find pleasure in the process of trying to find answers.

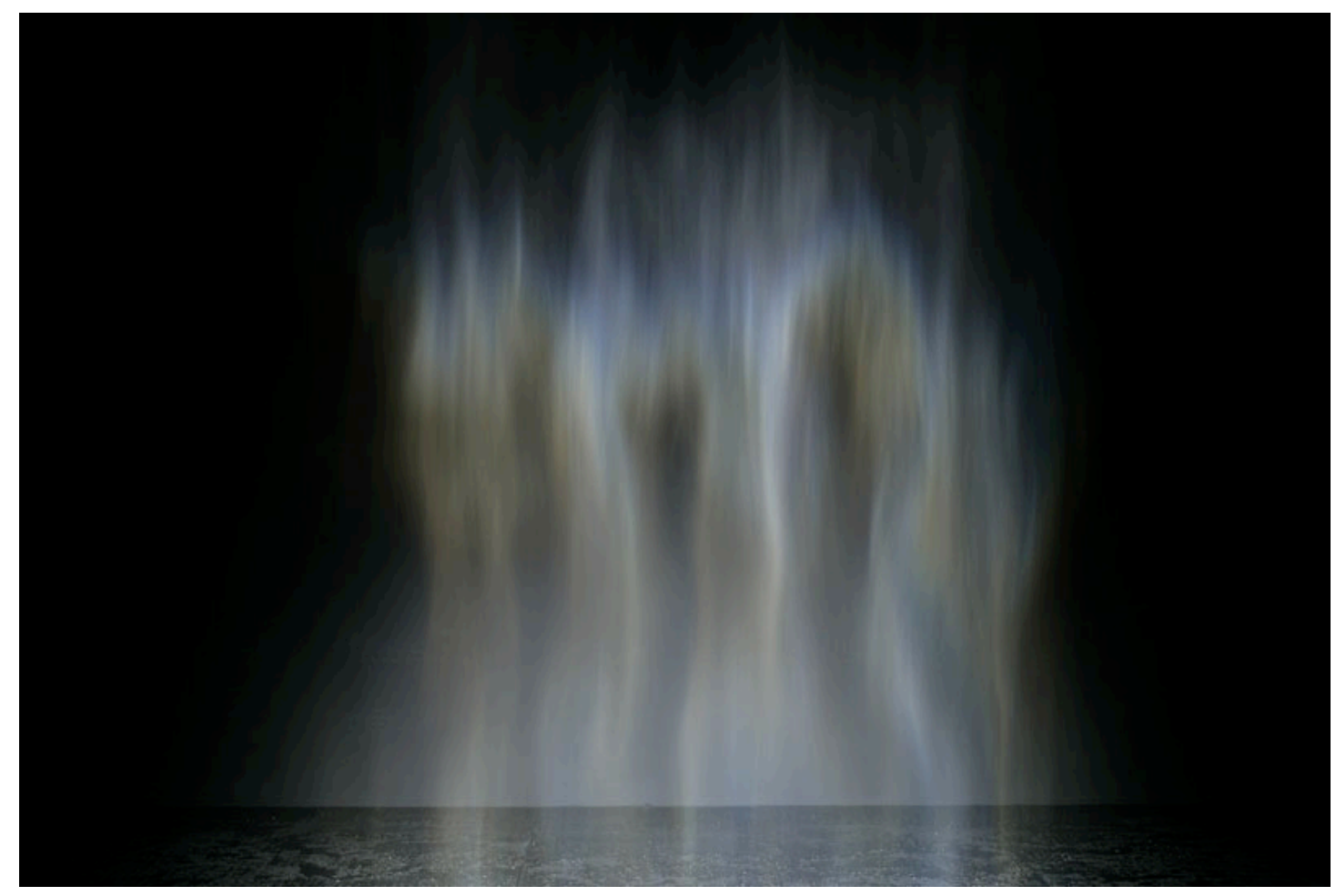

Fig 3. beauty

\section{IMPERMANENT ART}

Currently I am developing a piece of work that was originally shown at the University of Brighton, 2009 in an exhibition entitled 'Thinking Machines'. The aim of this piece was to encapsulate the essence of impermanent art. When entering the space, the viewer is presented with a sculpture in the form of a plant and a watering can. You are encouraged to water the plants leaves. Upon doing so, the plant responds by illuminating the areas that has just been watered and the corresponding flowers. As the light fades in, the plant also produces sound. Each light works independently and only lasts for a few seconds. Any light can be activated at anytime and simultaneously allowing the user to produce personalised ever-changing aesthetic. Imperfect in form, it represents something that is continuously evolving, life. 
The redevelopment of this piece will transform it into an outdoor space where it will react to natural elements, playfully demonstrating interaction that is beyond our intervention. The rain continues to excite and surprise us even though it may sometimes not be welcome. It can patter, descend in the finest mist and pour. The sculpture will both compliment and enhance the spontaneous nature of the rain.

When the idea of perfection can be achieved i.e. within the advances of technology, we find that there is an aesthetic need for imperfection. Beauty can then be found in something that is imperfect. Retrospective of Benjamin's analysis, mass reproduction preserves art replacing its presence in time and space with stillness and permanence and subsequently losing its aura. A look at improvisational and interactive art shows that modern technology can be both reproducible and hold a sense of authenticity. Using technology in a particular way provides uniqueness. Art becomes a tool, a machine, in which progression can occur and creativity and individuality can flourish. The pursuit of beauty in imperfection is the pursuit of beauty in impermanent, a concept that is associated with nature. The perception of beauty in nature and beauty in art are 'interdependent'.

t could also be said that beauty is not inherent in the object, or indeed in nature itself, it comes from the relationship we have with the art, as impermanent beings ourselves. In Impermanent art the beauty resides in an alternative space to the tradition idea of beauty. It isn't bound to an object as the object being observed transforms producing dynamic art.

This is true of wonder, the emotion that encourages our drive to gain knowledge and creates feelings of beauty and awe.

Technological progress is significant in aesthetical trends. This progress does two important things that lead to the appeal of impermanent art, especially within digital art. Firstly, technological progress leads to repetition in art. Secondly and subsequently, new technologies facilitate the need for new experience in contrast to the repetition.

...years or even centuries of intellectual work must already have taken place in a certain direction before there can be a reality that is viewed as ordinary and unexpected. Only this makes possible the rare and privileged moment... Fisher [4.2]

In the development of digital art forms, repetition and familiarity begin to make way for the experience of the rare and imperfect moments found within impermanent art. As we become increasingly knowledgeable about our environment, we look for pleasure in what we don't understand. With impermanent art and the model of a framework, modern art is beginning to accommodate for the 'new' experience of Beauty.

\section{References}

\section{Books/ Catalogues/ Essays}

[1] ASCOTT, ROY. Art, Technology, Consciousness: mind@large. 2000 Intellect Books, Bristol. p.g 94 
[2] BENTLEY, P, J AND CORNE, D, W: Creative evolutionary systems. 2001 Morgan Kaufmann Publishers Inc. San Francisco, CA.

[3] DESCARTES, R: The Passions of the Soul. Trans. Stephen H.Voss. 1989, Hackett Publishing Company.

[4] FISHER, PHILIP. Wonder, the rainbow, and the Aesthetics of Rare Experiences. 1998, Harvard University Press. [4.1] p.g 17 [4.2] p.g 57

[5] JUNIPER, A: Wabi Sabi: The Japanese Art of Impermanence. 2003, Tuttle Publishing p.g 2

[6] KANT, I: The Critique of Judgement, Trans. Meredith, J, C. 1982, Oxford University Press. Sec. 16

\section{Online/ Internet}

[7] BENJAMIN, W: The Work of Art in the Age of Mechanical Reproduction. Trans. Andy Blunden. 1998. 20 November 2009

http://www.softwaretipsandtricks.com/forum/windows-xp/113-how-stop-wordautomatically-inserting-hyperlinks.html

[8] COULTHARD, K: Looking for the Band: Walter Benjamin and the Mechanical Reproduction of Jazz. Critical Studies in Improvisation. 3, 1. 2007. 20 November 2009 http://www.criticalimprov.com/index.php/csieci/article/viewPDFInterstitial/82/4 $\underline{15}$

[9] HARMEN, G: Benjamin, Warhol and the Aura. The Pinocchio Theory.2005. 6 Jan. 2009. 20 November 2009

http://www.shaviro.com/Blog/?m=200510

[10] KRUEGER, MYRON. 1969 - VIDEOPLACE. 2. 2. 2004. 20 November 2009 http://www.jtnimoy.net/itp/newmediahistory/videoplace/

\section{Events/ Exhibitions/Artifacts}

[Fig. 2] Kirschner, Roman. Roots. Galerie Färbergasse, Vienna. 2008 http://www.romankirschner.net/index.php?roots

[Fig. 3] Eliasson, Olafur. beauty. The Museum of Contemporary Art.2003, Los Angeles.

[Fig. 1] Pask, Gordon: Colloquy of Mobiles. ICA. 1968, London 